\title{
The Relationship of Lifestyle Factors with the Prevalence of Major Depressive Disorder by Ecological Factors
}

\author{
Yeon-Jin Kim ${ }^{1}$ and Sang-Ah Lee $\mathrm{e}^{1,2} \bowtie$ \\ ${ }^{1}$ Department of Preventive Medicine, Kangwon National University School of Medicine, Chuncheon, Republic of Korea \\ ${ }^{2}$ Division of Epidemiology, Vanderbilt University Medical Center, Nashville, USA
}

Objective The association between ecological/lifestyle factors and major depressive disorder (MDD) have been provided but was inconsistent as characteristics of population including race, gender, etc.

Methods Data were extracted from the Korean National Health and Nutrition Examination Survey and consisted of 35,839 adults including 1,537 with MDD. Ecological factors included age, sex, married status, education, family income, residence, occupation, BMI, self-recognition stress, and history of non-communicable disease. Smoking, drinking, regular exercise, total energy intake, and sleep was consisted for lifestyle factors. The relationship between MDD and ecological/lifestyle factors, was evaluated using the multiple logistic regression model after adjustment for covariates.

Results The increased prevalence of MDD in men was related aged, unmarried, low educated, unoccupied, high BMI, and high selfrecognition stress. To women, MDD prevalence was increased as aged, low educated and family income, resided in urban, unoccupied, high self-recognition stress and history of non-communicable disease. Current smoking/drinking and lack of sleep was positively related with prevalence of MDD in women. The relationship between lifestyle factors and MDD prevalence was influenced by ecological status, predominantly in women.

Conclusion The relationship of lifestyle factors with MDD prevalence were observed and could be attenuated by various ecological factors, in women.

Psychiatry Investig 2021;18(4):340-347

Key Words Lifestyle factors, Prevalence of depression, Obese, Employment, Self-recognition of stress.

\section{INTRODUCTION}

Major depressive disorder (MDD) is a common mental illness that is a leading cause of major health problems worldwide, including lower quality of life, adverse effect of health and disease prognosis, all-cause mortality, and death from suicide. $^{1}$ Although the prevalence of depression in Asian countries is relatively lower than that of western countries, ${ }^{2}$ epidemiological surveys of mental disorders in Korea conducted every 5 years reported a gradual increase in the lifetime prevalence of major depressive disorder (MDD) since 2001. ${ }^{3}$ Due to the highest rate of Korean suicide in Organization for Eco-

Received: August 19, 2020 Revised: December 7, 2020

Accepted: January 15, 2021

$\triangle$ Correspondence: Sang-Ah Lee, PhD

Department of Preventive Medicine, Kangwon National University School of Medicine, 1 Kangwondaehak-gil, Chuncheon 24341, Republic of Korea

Tel: +82-33-250-8871, Fax: +82-33-259-5637

E-mail: sangahlee@kangwon.ac.kr

(a) This is an Open Access article distributed under the terms of the Creative Commons Attribution Non-Commercial License (https://creativecommons.org/licenses/by$\mathrm{nc} / 4.0$ ) which permits unrestricted non-commercial use, distribution, and reproduction in any medium, provided the original work is properly cited. nomic Cooperation and Development (OECD), the mental health including depression has been of interest to public health authority in Korea.

An epidemiological study reported that ecological and lifestyle factors may be related to the MDD; ${ }^{4}$ women, unmarried, and low educated, low income, or occupational prestige were likely to suffer by MDD. Education is the single variable that best explains the effect of age on MDD. Income is correlated with several other factors that have also been shown to correlate with depression symptomatology: education, race, gender, age, and occupation type. ${ }^{5}$ In particular, job loss is associated with increased depressive symptoms, which provides indirect evidence of the psychological benefits of paid employment. ${ }^{6}$ Residence area could associate with the prevalence of MDD: elderly in urban area was higher suffered by depressive symptoms (13.3\%), compare to rural. ${ }^{7}$

The MDD and lifestyle factors likely has a bidirectional relationship. The risk of alcohol dependence is significantly higher among individuals with depression than in the general population; ${ }^{8}$ conversely, depression is more prevalent among indi- 
viduals with alcohol dependence than those without dependence. ${ }^{9}$ Thirty percent of patients with MDD are current smokers, and smokers with a history of depression are twice as likely to be nicotine dependent as those without a depression history. ${ }^{10}$ Nevertheless, the magnitude and consistency of the smokingdepression relationship is not well characterized in adults. Some studies have supported the use of exercise to improve mood and reduce depressive symptoms, with stronger effects being seen in clinical depression. ${ }^{11}$ People with sleep disorders are associated with mental illnesses such as depression; in particular, insomnia was significantly related with the risk of developing depression. ${ }^{12}$

In recent, it is required further quantitative and qualitative studies to fully characterize the relationship between various aspects of socioeconomic circumstances and community, workplace, household, and lifestyle, because lifestyle factors could be affected by ecological status. Therefore, this study is aimed to evaluate the relationship between the MDD and ecological/ lifestyle factors, and to examine the attenuated effect by ecological status including age, married status, education level, family income, residence, occupation, BMI, and self-recognition of stress on the relationship.

\section{METHODS}

\section{Study population}

The Korea National Health and Nutrition Examination Survey (KNHANES) is a nationwide and multistage stratified crosssectional study of non-institutionalized Korean people, ${ }^{13}$ which is conducted every year by the Korea Centers for Disease Con- trol and Prevention (KCDC). Individuals are recruited using a multi-stage clustered probability design and the additional information about KNHANES are available elsewhere. ${ }^{13}$ The KNHANES consists of three parts: 1) health interview, 2) health examination, and 3) nutritional survey. Approximately 576 national districts were selected for the health interview survey, and 192 national districts were selected for the health examination survey and health behavior survey. Approximately 20 households from each district were included. The survey protocol was approved by the Institutional Review Board of the KCDC (2008-04EXP-01-C, 2009-01CON-03-2C, 2010-02CON21-C, 2011-02CON-06-C, 2012-01EXP-01-2C, 2013-07CON03-4C, 2013-12EXP-03-5C, 2015-01-02-6C). This study was based on data obtained in KNHANES IV (2008, 2009), V (20102012), and VI (2013-2015) and used health interview for using social economic state/life style variables, health examination to calculate the body mass index (BMI) and nutritional survey to investigate energy intake.

Initially, 61,379 participants were enrolled in KNHANES IV-VI. Among them, we excluded young participants (less than 18 years old, $n=14,620$ ), and participants without information of health interview $(n=7,652), \operatorname{MDD}(n=1,406)$, obesity $(\mathrm{n}=310)$, and diet $(\mathrm{n}=32)$. We excluded participants $(\mathrm{n}=$ 1,520 ) with an abnormal calorie intake ( $<800$ and $>4,000 \mathrm{kcal} /$ day for men $<500$ and $>3,500 \mathrm{kcal} /$ day for women). Finally, this study included 35,839 adults, including 1,537 MDD (Figure 1).

\section{Demographic and socioeconomic factors}

Self-administered structured questionnaires were used to obtain information regarding sociodemographic characteris-

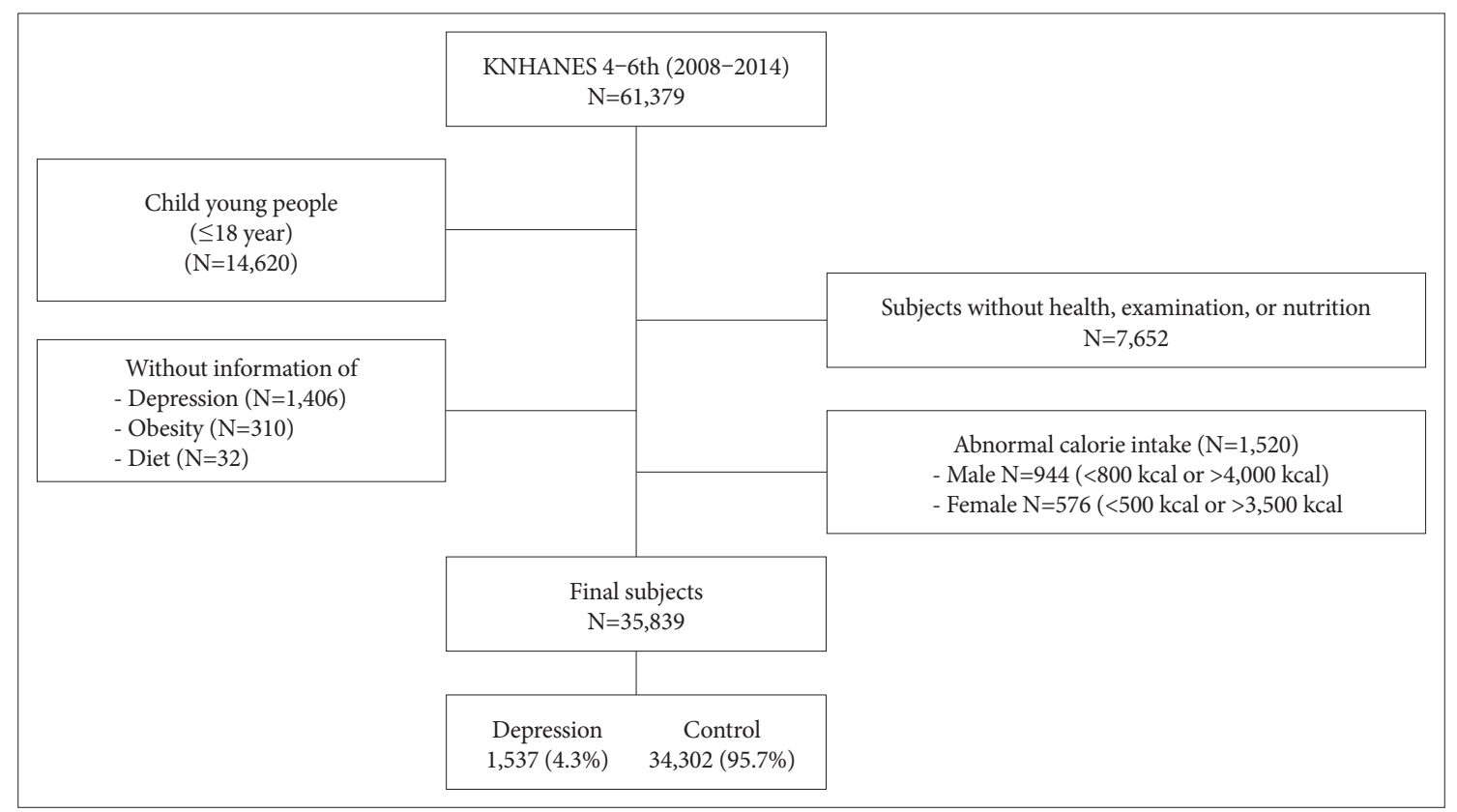

Figure 1. Subjects with depression included in the study. 
tics. Trained interviewers visited each household annually and conducted face-to-face interviews to obtain information during the KNHANES survey.

Each ecological status was categorized as follow: age $(<50$ vs. $\geq 50$ ), married status (single vs. couple), education ( $<12$ vs. $\geq 12$ years), family income ( $<3,000$ vs. $\geq 3,000$ dollars/month), residence (urban vs. rural), occupied (yes vs. no), self-recognition of stress (low vs. high), and non-communicable disease (yes vs. no). For the married status, single included separation, divorce, or widowed and couple included cohabitation. The self-recognition of stress was determined by the question "Do you usually feel stress to some extent in everyday life?" was evaluated by one question with four possible responses and categorized into one of two groups: low (very little and a little), high (somewhat and considerable). To define the history of non-communicable disease, we asked "Have you ever been diagnosed any non-communicable disease by physician including hypertension, hyperlipidemia, stroke, myocardial infarction, osteoarthritis, pulmonary tuberculosis, asthma, diabetes mellitus, thyroid dysfunction, stomach cancer, river cancer, colorectal cancer, breast cancer, uterine cervical cancer, lung cancer, thyroid cancer, any other cancer, atopic dermatitis, allergic rhinitis, renal failure, hepatitis $\mathrm{B}$, hepatitis $\mathrm{C}$ or liver cirrhosis?"

\section{Lifestyle factors}

Participants were asked about smoking status. Responses were never/former smoker and current smoker. Drinking status was classified as never/former and current. Drinking behavior was determined from self-administered questionnaires about drinking frequency over the past 12 months.

Alcohol drinking $(\mathrm{g} / \mathrm{d})$ were used to calculate the servings per month of alcoholic beverages by multiplying the frequency of alcohol consumption. Considering that a cup of pure alcohol content is about $10 \mathrm{~g}$, the average daily alcohol intake was calculated that the number of months was multiplied by 10 and then divided by the number of days per month. Alcohol drinking (g/d) was also estimated (gram per day): never/former, $<15 \mathrm{~g} / \mathrm{d}$ (small drinking) and $\geq 15 \mathrm{~g} / \mathrm{d}$ (high drinking).

Total energy intake was characterized from a 24-hour recall survey, which had been evaluated the relationship with the MDD using interquartile range (IQR). Participants were divided into three categories according to sleeping time based on recommended sleeping time: short sleeping time ( $\leq 6 \mathrm{~h} /$ day), adequate sleeping time (7-8 h/day), and long sleeping time ( $\geq 9 \mathrm{~h}$ /day). ${ }^{14}$ Regular exercise was defined as exercising more than once per week was divided into two groups (yes/no).

\section{Definition of MDD}

Health examinations were performed in local community health centers and clinics. Extensive data on health and nutri- tional status were collected using standardized high-quality methods including health interviews, dietary interviews, health examinations, and bio-specimen (blood and urine) analyses. To include clinically diagnosed MDD cases, we asked "Have you ever been diagnosed with depression confirmed by a physician?" Cases of MDD were defined as participants who answered "yes". Non-cases were defined as those who had never been diagnosed by a physician as having MDD.

\section{Anthropometric and clinical measurements}

Anthropometric indices were measured in participants wearing light clothes and not wearing shoes. Height was measured to the nearest $0.1 \mathrm{~cm}$ in the upright posture, and the body weight was measured to the nearest $0.1 \mathrm{~kg}$ in the upright posture. Body mass index (BMI) was calculated as body weight $(\mathrm{kg}) /$ square of height $\left(\mathrm{m}^{2}\right)$ and categorized as non-obese $\left(<25 \mathrm{~kg} / \mathrm{m}^{2}\right)$ and obese $\left(\geq 25 \mathrm{~kg} / \mathrm{m}^{2}\right){ }^{15}$

\section{Statistical analyses}

As KNHANES data were derived from multistage complex probability sampling to represent the entire Korean population, all estimates were calculated using sample weights based on geographical region, gender, and age groups; the sample weights were based on stratified cluster sampling. ${ }^{13}$ To estimate the relationship of lifestyle factors, we obtained odds ratios (ORs) and $95 \%$ confidence intervals (CIs) using multiple logistic regression model after adjustment for sex, age, married status, education level, occupation, family income, residence, BMI, self-recognition of stress, and non-communicable diseases. To evaluate the attenuated effect, we had an advanced analysis after stratified by ecological status including age, married status, level of education, family income, residence, occupation, BMI, and self-recognition of stress. Statistical analyses were performed using PROCSURVEY in SAS version 9.3 to account for the multistage and survey weightings when estimating all statistics. A probability value of $\mathrm{p}<0.05$ was considered statistically significant.

\section{RESULTS}

The prevalence of MDD increased with aging and living alone (i.e., unmarried and single) for men, but not for women (Table 1). Women were more likely to have experienced MDD than men $(\mathrm{POR}=2.46)$. The risk of MDD prevalence in men was increased as aged $(\mathrm{POR}=1.88)$, unmarried $(\mathrm{POR}=2.13)$, unoccupied ( $\mathrm{POR}=1.74)$, high $\mathrm{BMI}(\mathrm{POR}=1.54)$, and high selfrecognition stress $(\mathrm{POR}=2.64)$ but was decreased as highly educated $(\mathrm{POR}=0.67)$. The odds ratio of MDD prevalence was increased in women with aged $(\mathrm{POR}=1.36)$, unoccupied $(\mathrm{POR}=$ 1.33), high self-recognition stress $(\mathrm{POR}=2.74)$ and history of 
non-communicable disease $(\mathrm{POR}=1.38)$, but decreased with highly educated $(\mathrm{POR}=0.64)$, high family income $(\mathrm{POR}=0.76)$, and resided in rural $(\mathrm{POR}=0.76)$. No relationship of lifestyle factor with MDD was observed in men with exception of sleeping time ( $\mathrm{POR}=2.09)$ (Table 2). Otherwise, current smoking $(\mathrm{POR}=1.87)$, current drinking $(\mathrm{POR}=1.76)$ and lack of sleep time $(\mathrm{POR}=1.26)$ was positively related with prevalence of MDD in women.

The relationship between the lifestyle factors and MDD by ecological status in men (Table 3, Supplementary Tables 1 and 2 in the online-only Data Supplement) and in women (Table 4, Supplementary Tables 3 and 4 in the online-only Data Sup-

Table 1. General characteristics of study participants according to the major depressive disorder

\begin{tabular}{|c|c|c|c|c|c|c|}
\hline & \multicolumn{3}{|c|}{ Male } & \multicolumn{3}{|c|}{ Female } \\
\hline & $\begin{array}{c}\mathrm{MDD} \\
(\mathrm{N}=271)\end{array}$ & $\begin{array}{c}\text { Control } \\
(\mathrm{N}=13,807)\end{array}$ & POR & $\begin{array}{c}\text { MDD } \\
(\mathrm{N}=1,266)\end{array}$ & $\begin{array}{c}\text { Control } \\
(\mathrm{N}=20,495)\end{array}$ & POR \\
\hline Sex & & & & 76.2 & 50.8 & $2.46(2.08-2.91)$ \\
\hline Age (year) $(\geq 50)$ & 47.4 & 36.7 & $1.88(1.29-2.74)$ & 54.9 & 40.3 & $1.36(1.14-1.63)$ \\
\hline Married status (single) & 44.9 & 29.8 & $2.13(1.47-3.09)$ & 32.3 & 33.0 & $0.87(0.74-1.01)$ \\
\hline Education ( $\geq 12$ year) & 23.0 & 36.3 & $0.67(0.46-0.98)$ & 17.0 & 29.2 & $0.64(0.51-0.79)$ \\
\hline Income $(\geq \$ 3,000 /$ month $)$ & 39.9 & 51.6 & $0.85(0.60-1.20)$ & 38.1 & 49.2 & $0.82(0.70-0.97)$ \\
\hline Residence (rural) & 17.5 & 17.4 & $1.00(0.69-1.46)$ & 14.9 & 16.5 & $0.76(0.63-0.93)$ \\
\hline Unoccupied & 42.8 & 23.8 & $1.74(1.23-2.46)$ & 59.5 & 50.1 & $1.33(1.15-1.54)$ \\
\hline $\operatorname{BMI}\left(\mathrm{kg} / \mathrm{m}^{2}\right)(\geq 25)$ & 44.6 & 36.1 & $1.54(1.12-2.12)$ & 32.3 & 26.8 & $1.05(0.90-1.23)$ \\
\hline Self-recognition stress (high) & 42.7 & 23.8 & $2.64(1.93-3.60)$ & 50.3 & 27.9 & $2.74(2.38-3.15)$ \\
\hline His of $\mathrm{NCD}^{*}$ (yes) & 50.1 & 40.3 & $1.18(0.85-1.64)$ & 60.8 & 46.3 & $1.38(1.17-1.64)$ \\
\hline
\end{tabular}

*history of non-communicable disease. POR: prevalence of odds ratio after adjusted for sex, age, married status, education, occupation, family income, residence, body mass index, stress recognition, and history of non-communicable disease, MDD: major depressive disorder

Table 2. The association between the lifestyle factors and the major depressive disorder

\begin{tabular}{|c|c|c|c|c|c|c|}
\hline & \multicolumn{3}{|c|}{ Male } & \multicolumn{3}{|c|}{ Female } \\
\hline & $\begin{array}{c}\text { MDD } \\
(n=271)\end{array}$ & $\begin{array}{c}\text { Control } \\
(\mathrm{n}=13,807)\end{array}$ & POR & $\begin{array}{c}\text { MDD } \\
(\mathrm{n}=1,266)\end{array}$ & $\begin{array}{c}\text { Control } \\
(\mathrm{n}=20,495)\end{array}$ & POR \\
\hline Current smoking & 44.1 & 43.9 & $1.00(0.72-1.39)$ & 11.2 & 5.9 & $1.87(1.45-2.43)$ \\
\hline Current drinking & 78.7 & 85.8 & $0.69(0.47-1.00)$ & 63.6 & 66.4 & $1.12(0.96-1.31)$ \\
\hline$\geq 15$ (g/day) & 27.9 & 29.4 & $0.94(0.65-1.35)$ & 7.9 & 5.0 & $1.76(1.31-2.37)$ \\
\hline Exercise (yes) & 30.9 & 33.2 & $0.97(0.69-1.36)$ & 14.6 & 16.1 & $1.01(0.82-1.25)$ \\
\hline Total energy intake (IQR) & & & $1.08(0.85-1.36)$ & & & $1.04(0.91-1.18)$ \\
\hline \multicolumn{7}{|l|}{ Sleeping time (hour/day)* } \\
\hline$\leq 6$ & 39.6 & 40.0 & $1.09(0.78-1.52)$ & 49.9 & 39.9 & $1.26(1.08-1.48)$ \\
\hline $9 \leq$ & 15.8 & 7.0 & $2.09(1.30-3.35)$ & 9.2 & 8.7 & $1.23(0.94-1.59)$ \\
\hline
\end{tabular}

*ref=7-8 (hour/day). IQR: inter quartile range, POR: prevalence of odds ratio after adjusted for sex, age, married status, education, occupation, family income, residence, body mass index, stress recognition, and history of non-communicable disease, MDD: major depressive disorder

Table 3. The relationship between the lifestyle factors and major depressive disorder by ecological status in male (POR)

\begin{tabular}{|c|c|c|c|c|c|c|c|c|c|c|c|c|c|c|}
\hline & Age (year) & \multicolumn{2}{|c|}{ Married status } & \multicolumn{2}{|c|}{$\begin{array}{c}\text { Education } \\
\text { (year) }\end{array}$} & \multicolumn{2}{|c|}{$\begin{array}{c}\text { Income } \\
\text { (\$/month) }\end{array}$} & \multicolumn{2}{|c|}{$\begin{array}{c}\text { Residence } \\
\text { area }\end{array}$} & \multicolumn{2}{|c|}{ Occupied } & $\begin{array}{c}\text { BMI } \\
\left(\mathrm{kg} / \mathrm{m}^{2}\right)\end{array}$ & \multicolumn{2}{|c|}{ Stress* } \\
\hline & $50<\geq 50$ & Married & Single & $12<$ & $\geq 12$ & $3,000<$ & $\geq 3,000$ & Urban & Rural & Yes & No & $25<\geq 25$ & Low & High \\
\hline Current drinking & & & & & & & & & 0.26 & & & 0.60 & & \\
\hline$\geq 15$ (g/day) & & & & & & & & & 0.35 & & & & & \\
\hline $\begin{array}{l}\text { Sleeping time } \\
\quad(\text { hour/day, } \geq 9)^{\dagger}\end{array}$ & 2.68 & 2.19 & & & 4.58 & 2.34 & & 2.13 & & & 2.34 & 2.98 & & 2.78 \\
\hline
\end{tabular}

${ }^{*}$ self-recognition of stress, ${ }^{\dagger}$ ref=7-8 (hour/day). BMI: body mass index, POR: prevalence of odds ratio after adjusted for sex, age, married status, education, occupation, family income, residence, BMI, stress recognition, and history of non-communicable disease 
Table 4. The relationship between the lifestyle factors and major depressive disorder by ecological status in female (POR)

\begin{tabular}{|c|c|c|c|c|c|c|c|c|c|c|c|c|c|}
\hline & Age (year) & \multicolumn{2}{|c|}{ Married status } & $\begin{array}{c}\text { Education } \\
\text { (year) }\end{array}$ & \multicolumn{2}{|c|}{$\begin{array}{c}\text { Income } \\
\text { (\$/month) }\end{array}$} & $\begin{array}{c}\text { Residence } \\
\text { area }\end{array}$ & \multicolumn{2}{|c|}{ Occupied } & \multicolumn{2}{|c|}{$\begin{array}{c}\text { BMI } \\
\left(\mathrm{kg} / \mathrm{m}^{2}\right)\end{array}$} & \multicolumn{2}{|c|}{ Stress* } \\
\hline & $\overline{50<\geq 50}$ & Married & Single & $12<\geq 12$ & $3,000<$ & $\geq 3,000$ & Urban Rural & Yes & No & $25<$ & $\geq 25$ & Low & High \\
\hline Current smoking & 2.35 & 1.53 & 2.14 & 1.643 .19 & 1.69 & 2.23 & 1.99 & 2.03 & 1.74 & 1.59 & 2.55 & 1.54 & 1.99 \\
\hline Current drinking & & & & & & & & & 1.28 & & & & 1.31 \\
\hline$\geq 15$ (g/day) & 1.89 & 1.61 & 1.95 & 1.632 .18 & & 2.58 & 1.87 & 1.94 & 1.54 & 1.67 & 1.95 & & 2.27 \\
\hline Total energy intak & e (IQR) & & & & 1.18 & & & & & & & & \\
\hline \multicolumn{14}{|c|}{ Sleeping time (hour/day) ${ }^{\dagger}$} \\
\hline$\leq 6$ & 1.37 & 1.22 & 1.40 & 1.28 & 1.35 & & 1.28 & 1.41 & & 1.38 & & & 1.39 \\
\hline$\geq 9$ & & & & & & & & & & & & & 1.58 \\
\hline
\end{tabular}

*self-recognition of stress, ${ }^{\dagger}$ ref=7-8 (hour/day). BMI: body mass index, IQR: inter quartile range, POR: prevalence of odds ratio after adjusted for sex, age, married status, education, occupation, family income, residence, BMI, stress recognition, and history of non-communicable disease

plement). The relationship of current drinking with MDD was influenced by residence and BMI status and the relationship of sleep was attenuated by all ecological factors (Table 3); the increased prevalence of MDD with over sleep time was observed in young $(\mathrm{POR}=2.68)$, married $(\mathrm{POR}=2.19)$, highly educated (4.58), low family income ( $\mathrm{POR}=2.34)$, resided urban ( $\mathrm{POR}=2.13$ ), unoccupied ( $\mathrm{POR}=2.34$ ), normal body weight ( $\mathrm{POR}=2.98)$, and high self-recognition stress ( $\mathrm{POR}=2.78$ ). Current women smoker had experienced MDD regardless of married status, education, family income, occupation, BMI, and self-recognition stress, but women aged and resided in rural had not suffered by MDD (Table 4). The relationship between MDD and current drinking was observed in women without occupied and with high self-recognition stress; however, binge drinking ( $15 \mathrm{~g} /$ day $)$ was related to MDD prevalence regardless of married status, education, occupaton, and BMI, and was predominantly observed in young, high income, resided in urban and highly self-recognition stressed women. Women with low family income ( $<3,000$ dollar/month) was shown in high MDD prevalence as increased dietary total energy intake. Although lack of sleep time was related to MDD regardless of married status, young women or low educated, low family income, resided urban, occupation, and normal BMI were related to the prevalence of MDD only. High self-recognition stress was related with both lack and over sleep.

\section{DISCUSSION}

Although many large studies have suggested that the prevalence of depression increases linearly with age, ${ }^{16}$ the association remains unclear. In this study, the prevalence of MDD increased with aging in men and women. It is possible that the influence of physical, emotional, and social losses in the later years of life is moderated by an age-related adaptation. ${ }^{17}$ One key ecological factor that modifies depressive symptoms is married status in men; most research has shown that married peo- ple have better mental health than those who are single, widowed, separated, or divorced. ${ }^{18}$ In the present study, single men had a higher MDD than married men, regardless of the type of solitude, but this was not shown in women. Moen ${ }^{19}$ observed that the death of one's spouse might have a more deleterious emotional impact on men than women, which suggested that men derive more social and emotional support from marriage than women. In addition, the primary mechanisms linking widowhood to psychological distress among men could be related their difficulty in managing homemaking tasks, a lack of close personal relationships, and reliance on their spouses for health-maintenance behaviors and practices. ${ }^{20}$

More extensive education is a protective factor against depression, because education is related to coping and mastery, as well as to socioeconomic status, ${ }^{21}$ supported by our results. Otherwise, income inequality was unrelated to the prevalence of MDD in our study, in contrast to other reports. ${ }^{22}$ Although the importance of occupational stress in the workplace has been extensively studied, ${ }^{23}$ employment itself could be more likely to affect the MDD. Dooley et al. ${ }^{24}$ found that individuals who became unemployed faced more than twice the risk of increased depressive symptoms and an increased risk of becoming clinically depressed, compared to those who have been employed. Having a job and working is more conducive to a healthy life than staying at home without a job. ${ }^{25}$ The association between BMI and depression or anxiety have reported regardless of their disease status, other psychosocial and lifestyle factors ${ }^{26}$ but still remains controversial. In the present study, increased prevalence of MDD was observed only in extremely obese men (BMI $>25)$. Zhao et al..$^{15}$ suggested a bidirectional relationship between obesity and mental health. It has been reported that personal health deterioration resulting from obesity and discriminatory treatment that may arise in the workplace may impair their physical function, weaken the quality of life related to health, and even contribute to mental illness. ${ }^{27}$ $\mathrm{Lee}^{28}$ reported that the prevalence of psychiatric disorders was 
significantly higher for men with a $\mathrm{BMI}<18.5 \mathrm{~kg} / \mathrm{m}^{2}$ (underweight) or $\geq 40 \mathrm{~kg} / \mathrm{m}^{2}$ (class III obesity) compared to those with a normal BMI and suggested that depression has a strong relationship with decreased productivity.

Smoking is highly comorbid with both depression and anxiety disorder across different populations. ${ }^{29,30}$ Prospective studies have provided evidence that depression are associated with increased likelihood of smoking initiation, ${ }^{31}$ while smoking cessation appears to be associated with a short-term increase in depressive symptoms. ${ }^{32}$ In our study, an increase in the prevalence of MDD according to smoking status was observed only in women, consistent with a prior study of Japanese working women. ${ }^{33}$ It has been hypothesized that smoking may cause depression, ${ }^{34}$ possibly through an influence on neurotransmitter pathways. ${ }^{35}$ Several models may explain the high rate of smoking in people with depression: genetic factors, ${ }^{34}$ environmental influences, ${ }^{34}$ self-medication, ${ }^{36}$ and bidirectional causality. ${ }^{31}$ The relationship of smoking with MDD was influenced regardless of ecological status, with exception of age (under 50 years) and residence (urban).

Our results add to other evidence that depression must be considered when assessing women's vulnerability to heavy alcohol use. ${ }^{37}$ Alcohol dependence is more likely to follow MDD than precede it, which supports that alcohol serves as self-medication in MDD. Boden and Fergusson ${ }^{38}$ suggested that the depression due to the effect of alcohol misuse on an individual's socioeconomic and ecological condition could be caused alcohol use disorder (AUD). Alcohol misuse could be related with the demolition of the social community, loss of economic capability, and health problems, which is claimed as the association between the AUD and MDD. ${ }^{38}$ Otherwise, the relationship of alcohol consumption itself to the prevalence of MDD was presented in only unemployed or high self-recognition of stress women in the present study.

Inadequate (both over and less) sleep is associated with most health disability including morbidity ${ }^{39}$ and mortality. ${ }^{40}$ The pathophysiological mechanisms of both sleep disturbances and depression has been described through the regulation of sleep by the brain stem and thalamic nuclei. ${ }^{41}$ The relationship between prevalence of MDD and sleeping time was different according to gender in the present study; it was positively related with lack of sleep in women but with over sleep in men. Hafner et al. ${ }^{42}$ reported that a highly significant association between leptin levels and the combination of depressed mood and sleep disturbances in normal-weight women (BMI $\leq 25)$. One possible mechanism to explain the gender difference of leptin levels suggested that estrogen is an effective leptin inducer, similar to glucosteroids; steroid-induced secretion of leptin is greater in the adipose tissue of women than men. ${ }^{27}$

In the present study, the association between longer sleep- ing time and MDD disappeared after stratification by unoccupied in women, but still observed in unoccupied men; otherwise, the association between short sleeping time and MDD was present in occupied women. This relationship between short sleeping time and socioeconomic status may, at least in part, be attenuated by age, married status, level of education, family income, residence area, occupation, obesity status, and self-recognition of stress in this study. Long sleeping time (more than 9 hour) was also associated with a relatively high incidence of smoking, physical inactivity, and obesity (data not shown in result table). However, further studies are required to identify the causal directions of these relationships because this is not possible from cross-sectional data and whether factors such as poverty or educational attainment may also exert an influence on the relationship.

An underlying pathophysiological mechanism for overeating or a binge-eating disorder may be dysregulation of the hypothalamic-pituitary-adrenal axis, which stimulates food intake (through the neuropeptide Y system) and blunts the efficiency of inhibition of food intake (through the Leptin system), thereby increasing food intake and body fat accumulation. ${ }^{43}$ In this study, high energy intake was not related with prevalence of MDD in both gender, even in advanced analysis after stratified by any ecological factors with exception of family income in women. Socio-demographic factors may moderate the association between depression and $\mathrm{BMI} .{ }^{44}$ Among primary care populations, stressors of any type are the most significant predictors of depression, ${ }^{45}$ but the question for underlying mechanism remains. Our results supported a strong association between self-recognition of stress and prevalence of MDD as expected. The vast majority of research supporting a relationship between stress and depressive episodes has been based on episodic stressors that have negative or undesirable content. ${ }^{46}$

The study is subject to several limitations. First, it used a crosssectional design that does not allow for temporal or causal inferences. The causal sequence between several control variables and MDD was unclear; therefore, it is difficult to differentiate between risk factors and the prevalence of depression. It was not possible to determine whether lifestyle factors changed since the onset of MDD, or whether the prevalence of MDD is high among people with specific lifestyle. Nevertheless, our report is useful for understanding which difference of lifestyle factors between people experiencing MDD and those without depression. Second, the diagnosis of MDD in the population was based on self-report of whether individuals had previously received a diagnosis of MDD by physician, even the information of medication use for depression was not included in KNHANES. The prevalence of MDD in this study is $4.2 \%$, but, the prevalence is around 6.9\% in the United States. ${ }^{47}$ It is possible that Asian was reluctant to report their mental status 
compared to other ethnic groups. ${ }^{48}$ Therefore, this report might have underestimated depression and thereby generated false negatives regarding the diagnosis of depression. Third, respondent bias, particularly social desirability bias, influences participants to deny undesirable traits, and attribute socially desirable traits to them. ${ }^{49}$ Some individuals may over-report good behavior, while others may under-report bad, or undesirable behavior. ${ }^{50}$ In the case of lifestyle factors, people who experience depression may over-report memories of excess smoking and drinking, or that they have been unable to eat properly. In particular, the KNHANES was not informed nicotine dependence which is a better variable to evaluate the influence of smoking. Forth, several ecological (e.g., self-recognition stress) and lifestyle factor (e.g., sleeping time) could be affected by information or recall bias.

Despite these limitations, the present study also has several strengths. First, the results were based upon a national survey with a stratified multistage clustered probability design, which could well represent the Korean population. Second, few papers have considered Asian cultures or regions; nor are there many studies of MDD prevalence according to married status or socioeconomic status differences. To the best of our knowledge, this is the first Asian study to evaluate the relationship of lifestyle factors with the prevalence of MDD considering the attenuated effect by ecological factors according to the characteristics of large population study (KNHANES).

In conclusion, the prevalence of MDD was associated with lifestyle factors including smoking, binge drinking, total energy intake, and sleeping time, predominately in women; no lifestyle factor was related with the prevalence of MDD in men with exception of binge drinking and sleeping time. The relationship of lifestyle factors with MDD could be attenuated by ecological status predominantly in women.

\section{Supplementary Materials}

The online-only Data Supplement is available with this article at https://doi.org/10.30773/pi.2020.0309.

\section{Acknowledgments}

This work was supported by grants by the Kangwon National University (2017-2018). The funder had no role in any part of this manuscript or the decision to publish.

\section{Conflicts of Interest}

The authors have no potential conflicts of interest to disclose.

\section{Author Contributions}

Conceptualization: Sang-Ah Lee. Data curation: Yeon-Jin Kim. Formal analysis: Yeon-Jin Kim. Investigation: Sang-Ah Lee. Methodology: SangAh Lee, Yeon-Jin Kim. Project administration: Sang-Ah Lee. Resources: Sang-Ah Lee. Software: Yeon-Jin Kim. Supervision: Sang-Ah Lee. Validation: Sang-Ah Lee. Visualization: Yeon-Jin Kim. Writing_original draft: Yeon-Jin Kim, Sang-Ah Lee. Writing_-review \& editing: Sang-Ah Lee.

\section{ORCID iDs}

Yeon-Jin Kim

Sang-Ah Lee

https://orcid.org/0000-0002-6747-8346

https://orcid.org/0000-0002-5079-9733

\section{REFERENCES}

1. McKnight PE, Kashdan TB. The importance of functional impairment to mental health outcomes: a case for reassessing our goals in depression treatment research. Clin Psychol Rev 2009;29:243-259.

2. WHO. Depression and Oter Commen Mental Disorders. Geneva, Switzerland: World Health Organization; 2017.

3. Cho MJ, Seong SJ, Park JE, Chung IW, Lee YM, Bae A, et al. Prevalence and correlates of DSM-IV mental disorders in South Korean adults: the Korean epidemiologic catchment area study 2011. Psychiatry Investig 2015;12:164-170.

4. Weissman MM, Bland RC, Canino GJ, Faravelli C, Greenwald S, Hwu HG, et al. Cross-national epidemiology of major depression and bipolar disorder. JAMA 1996;276:293-299.

5. Zimmerman FJ, Katon W. Socioeconomic status, depression disparities, and financial strain: what lies behind the income-depression relationship? Health Econ 2005;14:1197-1215.

6. Egan M, Daly M, Delaney L. Adolescent psychological distress, unemployment, and the Great Recession: Evidence from the National Longitudinal Study of Youth 1997. Soc Sci Med 2016;156:98-105.

7. St John PD, Blandford AA, Strain LA. Does a rural residence predict the development of depressive symptoms in older adults? Can J Rural Med 2009;14:150-156.

8. Kessler RC, Nelson CB, McGonagle KA, Liu J, Swartz M, Blazer DG. Comorbidity of DSM-III-R major depressive disorder in the general population: results from the US National Comorbidity Survey. Br J Psychiatry Suppl 1996;(30):17-30.

9. Kessler RC, Crum RM, Warner LA, Nelson CB, Schulenberg J, Anthony JC. Lifetime co-occurrence of DSM-III-R alcohol abuse and dependence with other psychiatric disorders in the National Comorbidity Survey. Arch Gen Psychiatry 1997;54:313-321.

10. Ziedonis D, Hitsman B, Beckham JC, Zvolensky M, Adler LE, Audrain-McGovern J, et al. Tobacco use and cessation in psychiatric disorders: National Institute of Mental Health report. Nicotine Tob Res 2008;10:1691-1715.

11. Daley A. Exercise and depression: a review of reviews. J Clin Psychol Med Settings 2008;15:140-147.

12. Taylor DJ, Lichstein KL, Durrence HH, Reidel BW, Bush AJ. Epidemiology of insomnia, depression, and anxiety. Sleep 2005;28:1457-1464.

13. Kweon S, Kim Y, Jang MJ, Kim Y, Kim K, Choi S, et al. Data resource profile: the Korea National Health and Nutrition Examination Survey (KNHANES). Int J Epidemiol 2014;43:69-77.

14. Bixler E. Sleep and society: an epidemiological perspective. Sleep Med 2009;10(Suppl 1):S3-S6.

15. Zhao G, Ford ES, Dhingra S, Li C, Strine TW, Mokdad AH. Depression and anxiety among US adults: associations with body mass index. Int J Obes (Lond) 2009;33:257-266.

16. McDougall FA, Kvaal K, Matthews FE, Paykel E, Jones PB, Dewey ME, et al. Prevalence of depression in older people in England and Wales: the MRC CFA Study. Psychol Med 2007;37:1787-1795.

17. Wild B, Herzog W, Schellberg D, Lechner S, Niehoff D, Brenner H, et al. Association between the prevalence of depression and age in a large representative German sample of people aged 53 to 80 years. Int J Geriatr Psychiatry 2012;27:375-381.

18. Lapierre TA. Marital status and depressive symptoms over time-age and gender variations. Fam Relat 2009;58:404-416.

19. Moen P. A life course perspective on retirement, gender, and well-being. J Occup Health Psychol 1996;1:131-144.

20. Umberson D, Wortman CB, Kessler RC. Widowhood and depression: explaining long-term gender differences in vulnerability. J Health Soc Behav 1992;33:10-24. 
21. Stordal E, Mykletun A, Dahl AA. The association between age and depression in the general population: a multivariate examination. Acta Psychiatr Scand 2003;107:132-141.

22. Burns JK, Tomita A, Lund C. Income inequality widens the existing income-related disparity in depression risk in post-apartheid South Africa: Evidence from a nationally representative panel study. Health Place 2017;45:10-16.

23. Kim SY, Shin YC, Oh KS, Shin DW, Lim WJ, Cho SJ, et al. Gender and age differences in the association between work stress and incident depressive symptoms among Korean employees: a cohort study. Int Arch Occup Environ Health 2020;93:457-467.

24. Dooley D, Catalano R, Wilson G. Depression and unemployment: panel findings from the Epidemiologic Catchment Area study. Am J Community Psychol 1994;22:745-765.

25. Work lowers people's stress level. Available at: https://contemporaryfamilies.org/work-lowers-stress-levels/.Accessed May 22, 2014.

26. John U, Meyer C, Rumpf HJ, Hapke U. Relationships of psychiatric disorders with overweight and obesity in an adult general population. Obes Res 2005;13:101-109.

27. Casabiell X, Pineiro V, Peino R, Lage M, Camina J, Gallego R, et al. Gender differences in both spontaneous and stimulated leptin secretion by human omental adipose tissue in vitro: dexamethasone and estradiol stimulate leptin release in women, but not in men. J Clin Endocrinol Metab 1998;83:2149-2155.

28. Lee YM. Loss of productivity due to depression among Korean employees. J Occup Health 2010;52:389-394.

29. Leung J, Gartner C, Hall W, Lucke J, Dobson A. A longitudinal study of the bi-directional relationship between tobacco smoking and psychological distress in a community sample of young Australian women. Psychol Med 2012;42:1273-1282.

30. Moylan S, Jacka FN, Pasco JA, Berk M. Cigarette smoking, nicotine dependence and anxiety disorders: a systematic review of populationbased, epidemiological studies. BMC Med 2012;10:123.

31. Tjora T, Hetland J, Aaro LE, Wold B, Wiium N, Overland S. The association between smoking and depression from adolescence to adulthood. Addiction 2014;109:1022-1030.

32. Burgess ES, Brown RA, Kahler CW, Niaura R, Abrams DB, Goldstein $\mathrm{MG}$, et al. Patterns of change in depressive symptoms during smoking cessation: who's at risk for relapse? J Consult Clin Psychol 2002;70:356361.

33. Ikeda T, Nakata A, Takahashi M, Hojou M, Haratani T, Nishikido N, et al. Correlates of depressive symptoms among workers in small- and medium-scale manufacturing enterprises in Japan. J Occup Health 2009;51:26-37.
34. Boden JM, Fergusson DM, Horwood LJ. Cigarette smoking and depression: tests of causal linkages using a longitudinal birth cohort. Br J Psychiatry 2010;196:440-446.

35. Dome P, Lazary J, Kalapos MP, Rihmer Z. Smoking, nicotine and neuropsychiatric disorders. Neurosci Biobehav Rev 2010;34:295-342.

36. Fergusson DM, Goodwin RD, Horwood LJ. Major depression and cigarette smoking: results of a 21-year longitudinal study. Psychol Med 2003;33:1357-1367.

37. Dixit AR, Crum RM. Prospective study of depression and the risk of heavy alcohol use in women. Am J Psychiatry 2000;157:751-758.

38. Boden JM, Fergusson DM. Alcohol and depression. Addiction 2011; 106:906-914.

39. Hall MH, Muldoon MF, Jennings JR, Buysse DJ, Flory JD, Manuck SB. Self-reported sleep duration is associated with the metabolic syndrome in midlife adults. Sleep 2008;31:635-643.

40. Hublin C, Partinen M, Koskenvuo M, Kaprio J. Sleep and mortality: a population-based 22-year follow-up study. Sleep 2007;30:1245-1253.

41. Nofzinger EA. Functional neuroimaging of sleep. Semin Neurol 2005; 25:9-18.

42. Hafner S, Baumert J, Emeny RT, Lacruz ME, Thorand B, Herder C, et al. Sleep disturbances and depressed mood: a harmful combination associated with increased leptin levels in women with normal weight. Biol Psychol 2012;89:163-169.

43. Bjorntorp P. Do stress reactions cause abdominal obesity and comorbidities? Obes Rev 2001;2:73-86.

44. Friedman MA, Brownell KD. Psychological correlates of obesity: moving to the next research generation. Psychol Bull 1995;117:3-20.

45. Plieger T, Melchers M, Montag C, Meermann R, Reuter M. Life stress as potential risk factor for depression and burnout. Burnout Res 2015; 2:19-24.

46. Hammen C. Stress and depression. Annu Rev Clin Psychol 2005;1: 293-319.

47. Weinberger AH, Gbedemah M, Martinez AM, Nash D, Galea S, Goodwin $\mathrm{RD}$. Trends in depression prevalence in the USA from 2005 to 2015: widening disparities in vulnerable groups. Psychol Med 2018; 48:1308-1315.

48. Abe-Kim J, Takeuchi DT, Hong S, Zane N, Sue S, Spencer MS, et al. Use of mental health-related services among immigrant and US-born Asian Americans: results from the National Latino and Asian American Study. Am J Public Health 2007;97:91-98.

49. Nederhof AJ. Methods of coping with social desirability bias: a review. Eur J Soc Psychol 1985;15:263-280.

50. Furnham A. Response bias, social desirability and dissimulation. Pers Individ Diff 1986;7:385-400. 
Supplementary Table 1. The association between the socioeconomic/lifestyle factors and major depressive disorder in male (POR)

\begin{tabular}{|c|c|c|c|c|c|c|c|c|}
\hline & \multicolumn{2}{|c|}{ Age (year) } & \multicolumn{2}{|c|}{ Education (year) } & \multicolumn{2}{|c|}{$\mathrm{BMI}\left(\mathrm{kg} / \mathrm{m}^{2}\right)$} & \multicolumn{2}{|c|}{ Stress* } \\
\hline & $<50$ & $\geq 50$ & $<12$ & $\geq 12$ & $<25$ & $\geq 25$ & Low & High \\
\hline Current smoking & $1.17(0.71-1.92)$ & $0.80(0.53-1.21)$ & $0.96(0.65-1.41)$ & $1.18(0.61-2.26)$ & $0.86(0.57-1.30)$ & $1.17(0.69-1.99)$ & $1.06(0.68-1.67)$ & $0.96(0.60-1.55)$ \\
\hline Current drinking & $0.54(0.28-1.05)$ & $0.81(0.54-1.20)$ & $0.71(0.47-1.07)$ & $0.78(0.29-2.15)$ & $0.60(0.37-0.97)$ & $0.85(0.45-1.62)$ & $0.84(0.54-1.31)$ & $0.57(0.29-1.14)$ \\
\hline$\geq 15$ (g/day) & $0.98(0.55-1.75)$ & $0.90(0.58-1.39)$ & $0.91(0.60-1.38)$ & $1.09(0.52-2.28)$ & $0.70(0.43-1.16)$ & $1.29(0.73-2.26)$ & $0.98(0.59-1.61)$ & $0.93(0.54-1.62)$ \\
\hline Exercise (yes) & $1.02(0.61-1.68)$ & $0.92(0.60-1.42)$ & $0.96(0.64-1.43)$ & $1.09(0.56-2.11)$ & $1.30(0.85-1.99)$ & $0.65(0.36-1.15)$ & $0.97(0.62-1.53)$ & $1.02(0.62-1.68)$ \\
\hline Total energy intake (IQR) & $1.12(0.79-1.57)$ & $1.02(0.78-1.34)$ & $1.15(0.89-1.49)$ & $0.99(0.59-1.64)$ & $1.08(0.82-1.44)$ & $1.08(0.74-1.57)$ & $1.21(0.90-1.63)$ & $0.97(0.67-1.38)$ \\
\hline \multicolumn{9}{|l|}{ Sleeping time (hour/day) ${ }^{\dagger}$} \\
\hline$\leq 6$ & $0.92(0.54-1.57)$ & $1.28(0.85-1.92)$ & $1.10(0.75-1.62)$ & $1.13(0.58-2.23)$ & $1.26(0.82-1.94)$ & $0.91(0.54-1.54)$ & $1.16(0.76-1.78)$ & $1.02(0.61-1.69)$ \\
\hline$\geq 9$ & $2.68(1.33-5.37)$ & $1.57(0.85-2.90)$ & $1.67(0.96-2.90)$ & $4.58(1.79-11.70)$ & $2.98(1.69-5.23)$ & $1.20(0.50-2.90)$ & $1.54(0.77-3.08)$ & $2.78(1.38-5.62)$ \\
\hline
\end{tabular}

*self-recognition of stress, ${ }^{\dagger}$ ref=7-8 (hour/day). BMI: body mass index, IQR: inter quartile range, POR: prevalence odds ration after adjusted for sex, age, married status, education level, occupation, family income, residence area, BMI, self-recognition of stress, and non-communicable disease 
Supplementary Table 2. The association between the socioeconomic/lifestyle factors and major depressive disorder in male (POR)

\begin{tabular}{|c|c|c|c|c|c|c|c|c|}
\hline & \multicolumn{2}{|c|}{ Married status } & \multicolumn{2}{|c|}{ Income (\$/month) } & \multicolumn{2}{|c|}{ Residence area } & \multicolumn{2}{|c|}{ Occupied } \\
\hline & Married & Single & $<\$ 3,000$ & $\geq \$ 3,000$ & Urban & Rural & Yes & No \\
\hline Current smoking & $1.00(0.68-1.47)$ & $0.99(0.57-1.71)$ & $1.08(0.73-1.60)$ & $0.89(0.50-1.58)$ & $1.12(0.78-1.62)$ & $0.56(0.29-1.08)$ & $0.96(0.63-1.46)$ & $1.12(0.66-1.90)$ \\
\hline Current drinking & $0.66(0.42-1.03)$ & $0.78(0.39-1.57)$ & $0.77(0.50-1.20)$ & $0.53(0.27-1.03)$ & $0.90(0.58-1.41)$ & $0.26(0.13-0.56)$ & $0.67(0.38-1.18)$ & $0.79(0.47-1.32)$ \\
\hline$\geq 15$ (g/day) & $0.84(0.54-1.32)$ & $1.11(0.59-2.07)$ & $0.90(0.58-1.40)$ & $1.02(0.55-1.89)$ & $1.11(0.75-1.66)$ & $0.35(0.16-0.78)$ & $0.86(0.56-1.33)$ & $1.16(0.63-2.13)$ \\
\hline Exercise (yes) & $0.74(0.49-1.12)$ & $1.32(0.76-2.28)$ & $1.00(0.66-1.51)$ & $0.91(0.51-1.62)$ & $0.91(0.63-1.32)$ & $1.37(0.61-3.06)$ & $0.80(0.50-1.29)$ & $1.27(0.77-2.11)$ \\
\hline Total energy intake (IQR) & $1.01(0.77-1.32)$ & $1.17(0.80-1.71)$ & $1.03(0.75-1.42)$ & $1.13(0.79-1.60)$ & $1.12(0.86-1.46)$ & $0.87(0.53-1.46)$ & $1.20(0.91-1.59)$ & $0.97(0.64-1.45)$ \\
\hline \multicolumn{9}{|l|}{ Sleeping time (hour/day)* } \\
\hline$\leq 6$ & $1.40(0.94-2.08)$ & $0.75(0.42-1.34)$ & $1.15(0.76-1.75)$ & $1.02(0.58-1.79)$ & $1.09(0.75-1.60)$ & $1.10(0.56-2.16)$ & $1.08(0.69-1.68)$ & $1.15(0.70-1.88)$ \\
\hline$\geq 9$ & $2.19(1.18-4.06)$ & $1.95(0.93-4.12)$ & $2.34(1.33-4.13)$ & $1.68(0.71-3.98)$ & $2.13(1.26-3.59)$ & $2.03(0.71-5.83)$ & $1.63(0.78-3.41)$ & $2.34(1.17-4.65)$ \\
\hline
\end{tabular}

${ }^{*}$ ref $=7-8$ (hour/day). IQR: inter quartile range, POR: prevalence odds ration after adjusted for sex, age, married status, education level, occupation, family income, residence area, body mass index, self-recognition of stress, and non-communicable disease 
Supplementary Table 3. The association between the socioeconomic/lifestyle factors and major depressive disorder in female (POR)

\begin{tabular}{|c|c|c|c|c|c|c|c|c|}
\hline & \multicolumn{2}{|c|}{ Age (year) } & \multicolumn{2}{|c|}{ Education (year) } & \multicolumn{2}{|c|}{$\mathrm{BMI}\left(\mathrm{kg} / \mathrm{m}^{2}\right)$} & \multicolumn{2}{|c|}{ Stress* } \\
\hline & $<50$ & $\geq 50$ & $<12$ & $\geq 12$ & $<25$ & $\geq 25$ & Low & High \\
\hline Current smoking & $2.35(1.70-3.25)$ & $1.01(0.67-1.53)$ & $1.64(1.24-2.17)$ & $3.19(1.72-5.90)$ & $1.59(1.16-2.20)$ & $2.55(1.70-3.81)$ & $1.54(1.00-2.36)$ & $1.99(1.41-2.82)$ \\
\hline Current drinking & $1.04(0.80-1.36)$ & $1.14(0.95-1.38)$ & $1.10(0.92-1.30)$ & $1.17(0.80-1.73)$ & $1.06(0.88-1.29)$ & $1.27(0.98-1.64)$ & $0.97(0.79-1.18)$ & $1.31(1.04-1.65)$ \\
\hline$\geq 15$ (g/day) & $1.89(1.34-2.67)$ & $1.22(0.69-2.17)$ & $1.63(1.17-2.27)$ & $2.18(1.13-4.21)$ & $1.67(1.14-2.45)$ & $1.95(1.16-3.26)$ & $1.01(0.61-1.68)$ & $2.27(1.52-3.38)$ \\
\hline Exercise (yes) & $0.98(0.71-1.36)$ & $1.04(0.79-1.36)$ & $1.02(0.81-1.28)$ & $0.93(0.58-1.51)$ & $0.89(0.69-1.16)$ & $1.32(0.94-1.84)$ & $0.97(0.74-1.28)$ & $1.06(0.77-1.45)$ \\
\hline Total energy intake (IQR) & $0.99(0.80-1.23)$ & $1.06(0.91-1.24)$ & $1.06(0.93-1.22)$ & $0.93(0.66-1.32)$ & $1.00(0.84-1.18)$ & $1.13(0.92-1.39)$ & $0.98(0.83-1.17)$ & $1.08(0.89-1.31)$ \\
\hline \multicolumn{9}{|l|}{ Sleeping time (hour/day) ${ }^{\dagger}$} \\
\hline$\leq 6$ & $1.37(1.06-1.78)$ & $1.18(0.98-1.42)$ & $1.28(1.08-1.52)$ & $1.21(0.81-1.82)$ & $1.38(1.14-1.66)$ & $1.05(0.80-1.36)$ & $1.17(0.96-1.43)$ & $1.39(1.09-1.77)$ \\
\hline$\geq 9$ & $1.38(0.94-2.04)$ & $1.03(0.74-1.43)$ & $1.21(0.90-1.63)$ & $1.30(0.75-2.28)$ & $1.26(0.91-1.73)$ & $1.16(0.76-1.79)$ & $0.96(0.67-1.39)$ & $1.58(1.07-2.34)$ \\
\hline
\end{tabular}

*self-recognition of stress, ${ }^{\dagger}$ ref=7-8 (hour/day). BMI: body mass index, IQR: inter quartile range, POR: prevalence odds ration after adjusted for sex, age, married status, education level, occupation, family income, residence area, BMI, self-recognition of stress, and non-communicable disease 
Supplementary Table 4. The association between the socioeconomic/lifestyle factors and major depressive disorder in female (POR)

\begin{tabular}{|c|c|c|c|c|c|c|c|c|}
\hline & \multicolumn{2}{|c|}{ Married status } & \multicolumn{2}{|c|}{ Income (\$/month) } & \multicolumn{2}{|c|}{ Residence area } & \multicolumn{2}{|c|}{ Occupied } \\
\hline & Married & Single & $<\$ 3,000$ & $\geq \$ 3,000$ & Urban & Rural & Yes & No \\
\hline Current smoking & $1.53(1.05-2.22)$ & $2.14(1.48-3.10)$ & $1.69(1.24-2.29)$ & $2.23(1.39-3.56)$ & $1.99(1.50-2.64)$ & $1.10(0.59-2.06)$ & $2.03(1.35-3.04)$ & $1.74(1.26-2.40)$ \\
\hline Current drinking & $1.06(0.88-1.29)$ & $1.20(0.92-1.56)$ & $1.16(0.96-1.40)$ & $1.04(0.80-1.36)$ & $1.13(0.94-1.35)$ & $1.10(0.79-1.53)$ & $0.89(0.70-1.13)$ & $1.28(1.06-1.55)$ \\
\hline$\geq 15$ (g/day) & $1.61(1.09-2.39)$ & $1.95(1.22-3.11)$ & $1.29(0.86-1.93)$ & $2.58(1.65-4.04)$ & $1.87(1.37-2.56)$ & $1.04(0.50-2.19)$ & $1.94(1.27-2.97)$ & $1.54(1.01-2.36)$ \\
\hline Exercise (yes) & $1.00(0.79-1.26)$ & $1.03(0.67-1.56)$ & $0.95(0.72-1.25)$ & $1.07(0.79-1.45)$ & $1.00(0.80-1.26)$ & $1.21(0.72-2.05)$ & $1.00(0.73-1.38)$ & $1.02(0.78-1.33)$ \\
\hline Total energy intake (IQR) & $1.04(0.89-1.22)$ & $1.03(0.81-1.32)$ & $1.18(1.02-1.37)$ & $0.84(0.67-1.05)$ & $1.05(0.91-1.21)$ & $0.92(0.70-1.21)$ & $0.99(0.80-1.22)$ & $1.06(0.89-1.25)$ \\
\hline \multicolumn{9}{|l|}{ Sleeping time (hour/day)* } \\
\hline$\leq 6$ & $1.22(1.01-1.46)$ & $1.40(1.05-1.88)$ & $1.35(1.10-1.65)$ & $1.16(0.91-1.49)$ & $1.28(1.07-1.52)$ & $1.22(0.90-1.64)$ & $1.41(1.11-1.80)$ & $1.17(0.96-1.43)$ \\
\hline$\geq 9$ & $1.20(0.88-1.64)$ & $1.28(0.81-2.02)$ & $1.36(0.99-1.87)$ & $1.01(0.64-1.60)$ & $1.23(0.91-1.66)$ & $1.13(0.70-1.83)$ & $1.27(0.82-1.98)$ & $1.19(0.86-1.64)$ \\
\hline
\end{tabular}

${ }^{*}$ ref $=7-8$ (hour/day). IQR: inter quartile range, POR: prevalence odds ration after adjusted for sex, age, married status, education level, occupation, family income, residence area, body mass index, self-recognition of stress, and non-communicable disease 